13,05

\title{
Влияние напряжения смещения и скорости осаждения на структуру и коэрцитивность пленок NiFe
}

\author{
(C) А.С. Джумалиев ${ }^{1,2}$, С.Л. Высоцкий ${ }^{1,2}$, В.К. Сахаров ${ }^{1}$ \\ ${ }^{1}$ Саратовский фолиал Института радиотехники и электроники В.А. Котельникова РАН, \\ Саратов, Россия \\ ${ }^{2}$ Саратовский государственный университет им. Н.Г. Чернышевского, \\ Саратов, Россия \\ E-mail: dzhas@yandex.ru
}

Поступила в Редакцию 30 июля 2020 г.

В окончательной редакции 30 июля 2020 г.

Принята к публикации 30 июля 2020 г.

Исследовано влияние напряжения смещения $U_{b}$ и скорости осаждения $v$ на структуру, размер зерна $D$ и коэрцитивность $H_{c}$ пленок $\mathrm{NiFe}$ толщиной $d$ от 30 до $980 \mathrm{~nm}$, выращенных на подложках $\mathrm{Si} / \mathrm{SiO}_{2}$ магнетронным распылением на постоянном токе. В случае $U_{b}=0$, снижение $v$ от значений $v \approx 27 \mathrm{~nm} / \mathrm{min}$ до $v \approx 7 \mathrm{~nm} / \mathrm{min}$ сопровождается ростом значений критической толщины пленок $d_{\text {cr }}$ от $d_{\text {cr }} \approx 220 \mathrm{~nm}$ до $d_{\text {cr }} \approx 270 \mathrm{~nm}$. При этом $H_{c}$ в пленках с $d<d_{\text {cr }}$ характеризуется зависимостью $H_{c} \sim D^{6}$ и меняется от $\sim 1$ до $\sim 20$ Ое. В случае $U_{b}=-100 \mathrm{~V}$ влияние скорости осаждения на коэрцитивность гораздо заметнее. При $v=7$ и $14 \mathrm{~nm} / \mathrm{min}$ пленки демонстрируют магнитомягкие свойства $\left(H_{c} \approx 0.15-1.4 \mathrm{Oе}\right)$ и отсутствие $d_{\mathrm{cr}}$ для всего диапазона исследованных толщин. Пленки, полученные при $v=21$ и $27 \mathrm{~nm} / \mathrm{min}$, переходят в „закритическое“ состояние при $d \geq d_{\mathrm{cr}} \approx 520 \mathrm{~nm}$, а в области $d<d_{\mathrm{cr}}$ характеризуются зависимостью $H_{c} \sim D^{3}$ и ростом коэрцитивности от $\sim 0.35$ до $\sim 10 \mathrm{Oе}$.

Ключевые слова: пленки $\mathrm{NiFe,} \mathrm{коэрцитивность,} \mathrm{„критическая“} \mathrm{толщина.}$

DOI: $10.21883 /$ FTT.2020.12.50221.163

\section{1. Введение}

Магнитомягкие пленки $\mathrm{NiFe}$, обладая низкой величиной коэрцитивности, высокой магнитной восприимчивостью, малой магнитострикцией и высоким магнитосопротивлением, широко используются в качестве магниточуствительного материала в сенсорных устройствах, в устройствах хранения и записи информации [1-3]. Однако с ростом толщины пленки $\mathrm{NiFe} \mathrm{утрачивают} \mathrm{свои}$ магнитомягкие свойства, что проявляется в росте величины коэрцитивности $H_{c}$ до максимального значения при толщине пленки $d$ равной некоторой „критической“

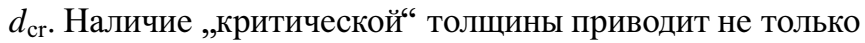
к росту коэрцитивности, но и к появлению полосовой доменной структуры [4], вращающейся [5] и перпендикулярной [6] магнитной анизотропии. Существование „критической“ толщины и перпендикулярной магнитной анизотропии представляет интерес как способ увеличения плотности записи информации, но ограничивает применение пленок $\mathrm{NiFe}$ в качестве магниточуствительного слоя. Зависимость величины $H_{c}$ от толщины пленки может быть использована при конструировании различных устройств спинтроники в которых применение ферромагнитных слоев с различной коэрцитивностью является необходимым условием. Перечисленные свойства пленок $\mathrm{NiFe}$ стимулируют поиск путей управления величиной $d_{\mathrm{cr}}$.

К причинам, приводящим к появлению $d_{\mathrm{cr}}$, относят магнитную кристаллографическую анизотропию, магнитострикцию, анизотропию формы микроструктуры плен- ки, а также рост размера $D$ зерен $[4,7-10]$. При этом, микроструктурное строение пленок во многом определяется технологическими параметрами осаждения пленок и свойствами подложки. По этой причине исследованию механизмов формирования микроструктурного строения пленок пермаллоя обеспечивающих рост значений $d_{\mathrm{cr}}$ уделяется определенное внимание. Так в работах $[11,12]$ показано, что улучшение текстуры пленок за счет напыления дополнительного слоя немагнитного материала приводит к снижению $H_{c}$. В работе [13] описано как улучшение текстуры пленок $\mathrm{FeNi}$ за счет снижения давления рабочего газа с $1.8 \cdot 10^{-2}$ до $2.8 \cdot 10^{-3} \mathrm{mbar}$ приводит к уменьшению $H_{c}$ и росту $d_{\text {cr }}$ с 50 до $220 \mathrm{~nm}$. Повышение температуры подложки от комнатной до $100^{\circ} \mathrm{C}$ приводит к увеличению критической толщины с $\sim 83$ до $\sim 166 \mathrm{~nm}[4]$, что объясняется уменьшением константы анизотропии. Вопросам совместного влияния потенциала смещения подложки $U_{b}$ и скорости осаждения пленки $v$ уделялось существенно меньше внимания. Возможность получения магнитомягких пленок $\mathrm{FeNi}$ толщиной $1 \mu \mathrm{m}$ применением ВЧ напряжения смещения $U_{b}$ от -120 до $-160 \mathrm{~V}$ при высокоскоростном напылении (> $150 \mathrm{~nm} / \mathrm{min})$ в установке с двумя магнетронами показана в работе [14]. Полученные результаты связываются с уменьшением внутренних напряжений и улучшением однородности пленок. В работе [15] исследовалось влияние скорости осаждения на свойства пленок пермаллоя толщиной $d=100 \mathrm{~nm}$, выращенных при отсутствии потенциала смещения $\left(U_{b}=0\right)$. При $v=10,18$ и $28 \mathrm{~nm} / \mathrm{min}$ величина $H_{c}$ равнялась 1.3 , 
1.1 и $1.4 \mathrm{Oе}$, соответственно. Представляет интерес исследовать механизм формирования магнитомягких пленок в условиях одновременного изменения параметров $U_{b}$ и $v$.

Следует также отметить, что исследование характера зависимости $H_{c}$ пленок докритических толщин $\left(d<d_{\mathrm{cr}}\right)$ от размера зерна $D$ позволяет связать механизм формирования коэрцитивности $[6,16,17]$ либо с доминированием магнитокристаллической анизотропии кристаллитов $\left(H_{c} \propto D^{6}\right)$, либо с преобладанием когерентной одноосной анизотропии над случайной магнитокристаллической $\left(H_{c} \propto D^{3}\right)$. Применительно к пленкам пермаллоя ранее наблюдалась лишь зависимость $H_{c} \propto D^{6}$ [10]. Представляет интерес поиск условий осаждения при которых в пленках пермаллоя зависимость $H_{c}(D)$ может изменяться по закону $D^{3}$.

С учетом сказанного, целью настоящей работы было исследование влияния параметров $U_{b}$ и $v$ на микроструктурное строение, коэрцитивность и характер зависимости $H_{c}$ от размера зерна для пленок пермаллоя толщиной от 30 до $980 \mathrm{~nm}$, выращенных магнетронным распылением на постоянном токе на подложках $\mathrm{Si} / \mathrm{SiO}_{2}$.

\section{2. Эксперимент}

Осаждение пленок $\mathrm{NiFe}$ проводилось в вакуумной установке ВУП-5М с базовым давлением $6 \cdot 10^{-4} \mathrm{~Pa}$ с помощью планарной магнетронной распылительной системы на постоянном токе при температуре окружающей среды. Для напыления использовались мишени $\mathrm{Ni}_{81} \mathrm{Fe}_{19}$ чистотой $99.95 \%$ (K. Lesker) и аргон марки ОЧ (99.998\%). Давление рабочего газа аргона во время напыления составляло $\sim 0.2 \mathrm{~Pa}$. Подложка размешалась над центром мишени на расстоянии $\sim 75 \mathrm{~mm}$. В качестве подложек использовались кремниевые пластины $\mathrm{Si}(100)$ марки 100КДБ12(100) с термически окисленным слоем $\mathrm{SiO}_{2}$ толщиной $300 \mathrm{~nm}$ и среднеквадратичной шероховатостью поверхности $\sigma \approx 0.3 \mathrm{~nm}$. Подложки подвергались предварительной ультразвуковой очистке в ацетоне при температуре $T \approx 315 \mathrm{~K}$ и термическому отжигу в вакууме при $T \approx 650 \mathrm{~K}$ в течение $30 \mathrm{~min}$. Толщина пленок определялась по времени и предварительно определенной скорости осаждения.

Кристаллическая структура пленок изучалась методом рентгеновской дифракции на дифрактометре ДРОН-4 с фокусировкой по плоскому образцу в геометрии Брэгга-Брентано (схема $\theta-2 \theta \mathrm{Cu}-K_{\alpha}$-излучение, $\lambda=0.15418 \mathrm{~nm}$ ). Микроструктура пленок изучалась методом сканирующей электронной микроскопии (СЭМ) (Auriga, Carl Zeiss). Толщина пленок определялась методом профилометрии (Dectak 150, Veeco). Величина коэрцитивности определялась по петлям гистерезиса, полученным методом вибромагнитометрии в касательной к поверхности пленки геометрии намагничивания при комнатной температуре.

Были изучены несколько серий образцов, полученных при $U_{b}=0$ и $-100 \mathrm{~V}$ и скоростях осаждения $v=7,14$,
21 и $27 \mathrm{~nm} / \mathrm{min}$. Увеличение скорости осаждения проводилось путем увеличения тока разряда от 85 до $200 \mathrm{~mA}$, при соответствующем изменении напряжения разряда от 345 до $380 \mathrm{~V}$.

\section{3. Результаты и обсуждение}

На рис. 1 показана зависимость поля коэрцитивности $H_{c}$ от толщины $d$ для пленок, выращенных при различных скоростях осаждения и $U_{b}=0$ и $-100 \mathrm{~V}$. Видно, что для пленок, выращенных при $U_{b}=0$, изменение скорости напыления от 7 до $14 \mathrm{~nm} / \mathrm{min}$ приводит к уменьшению „критической“ толщины с $\sim 270$ до $\sim 220 \mathrm{~nm}$, при соответствующем изменении максимального значения $H_{c}$ от 20.2 до 21.6 Ое. В обоих случаях минимальное значение $H_{c} \approx 1$ Ое. Полученные результаты совпадают с результатами работы [4], где уменьшение $d_{\mathrm{cr}}$ свя-

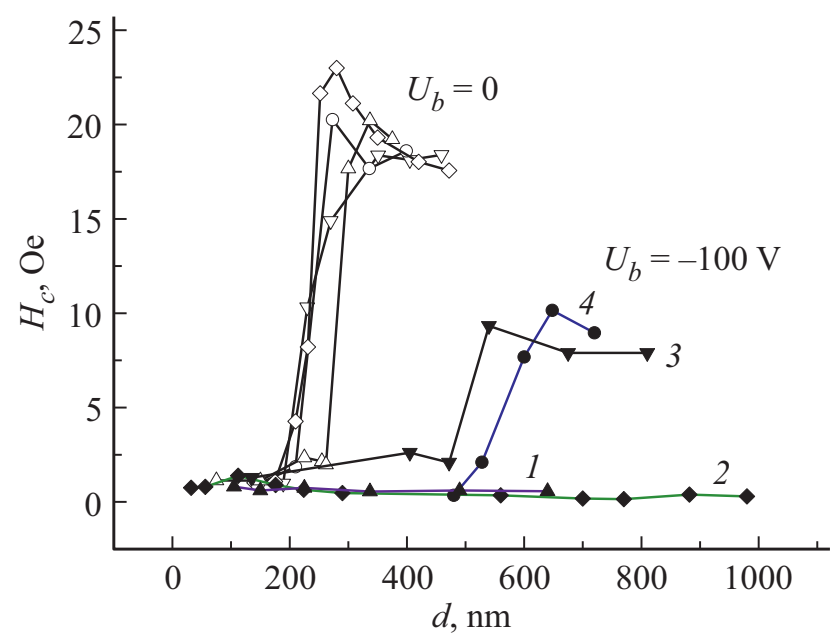

Рис. 1. Зависимость коэрцитивности $H_{c}$ от толщины пленок $d$, выращенных при различных $U_{b}$ и скоростях роста $v$. $1-v=7 \mathrm{~nm} / \mathrm{min}, 2-v=14 \mathrm{~nm} / \mathrm{min}, 3-v=21 \mathrm{~nm} / \mathrm{min}$, $4-v=27 \mathrm{~nm} / \mathrm{min}$.

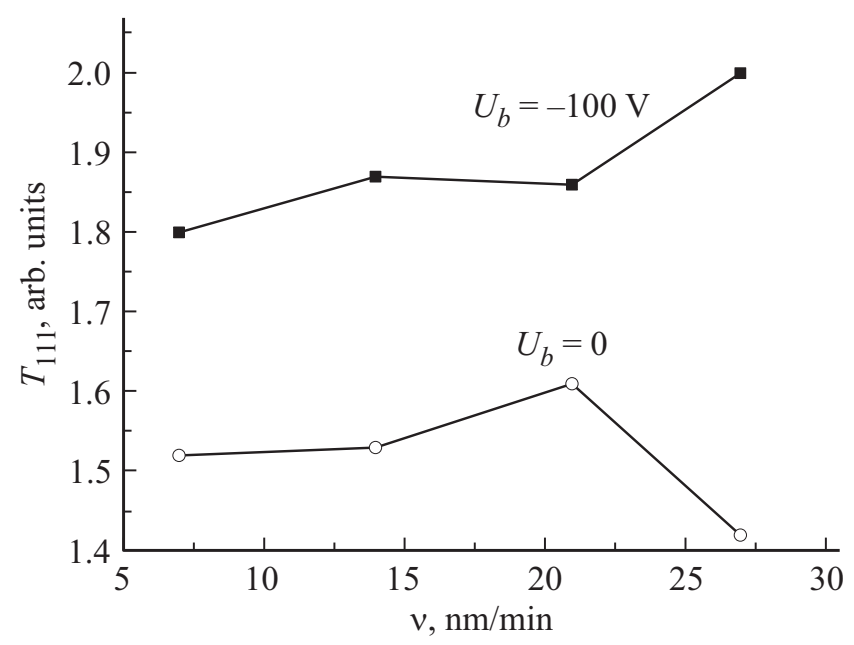

Рис. 2. Зависимость коэффициента текстуры $T_{111}$ от скорости осаждения $v$ и напряжения смещения $U_{b}$. 
$a$

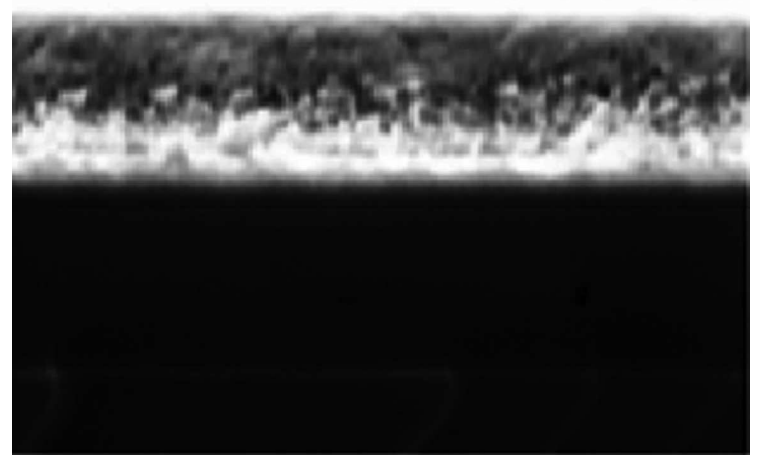

$d=337 \mathrm{~nm}$
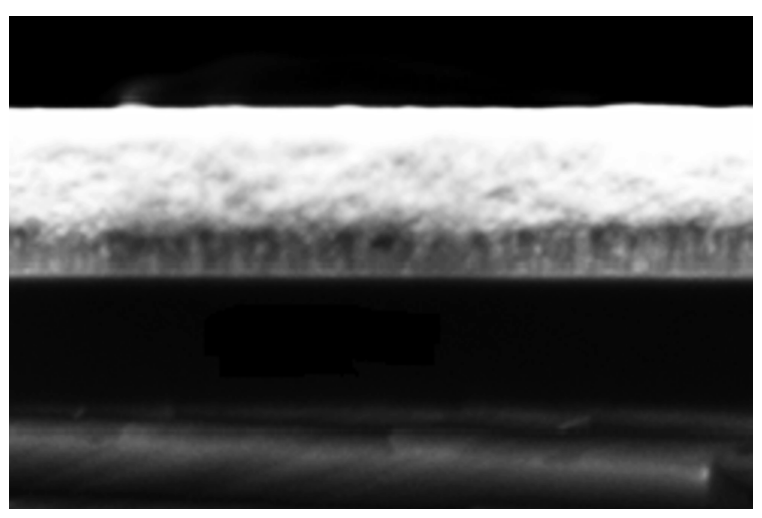

$d=420 \mathrm{~nm}$

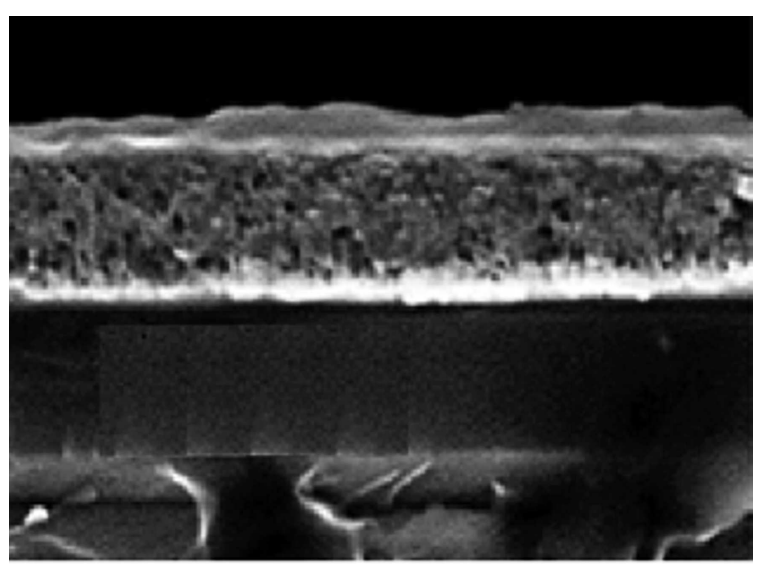

$d=350 \mathrm{~nm}$

$v=7 \mathrm{~nm} / \mathrm{min}$

$b$
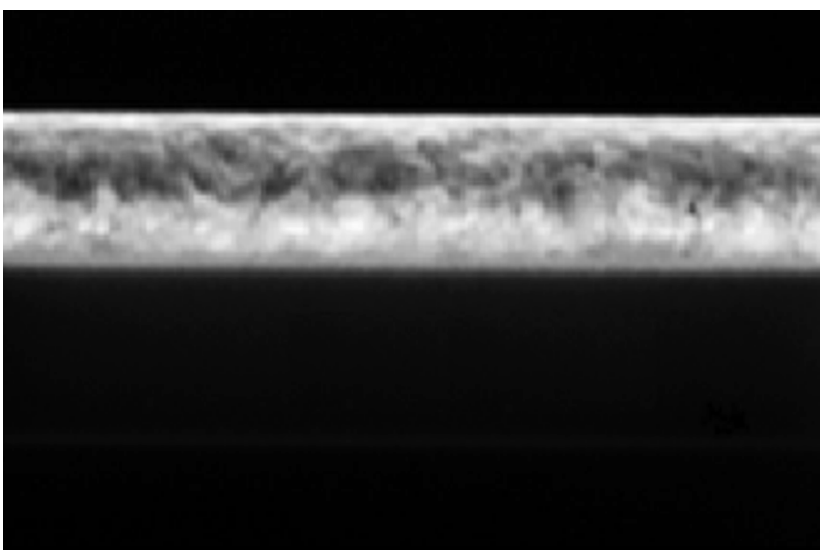

$d=337 \mathrm{~nm}$
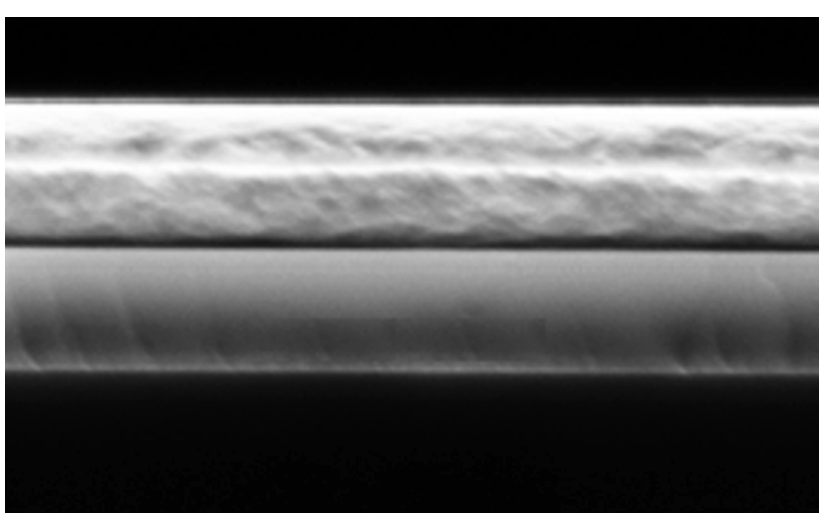

$v=14 \mathrm{~nm} / \mathrm{min}$

$d=483 \mathrm{~nm}$

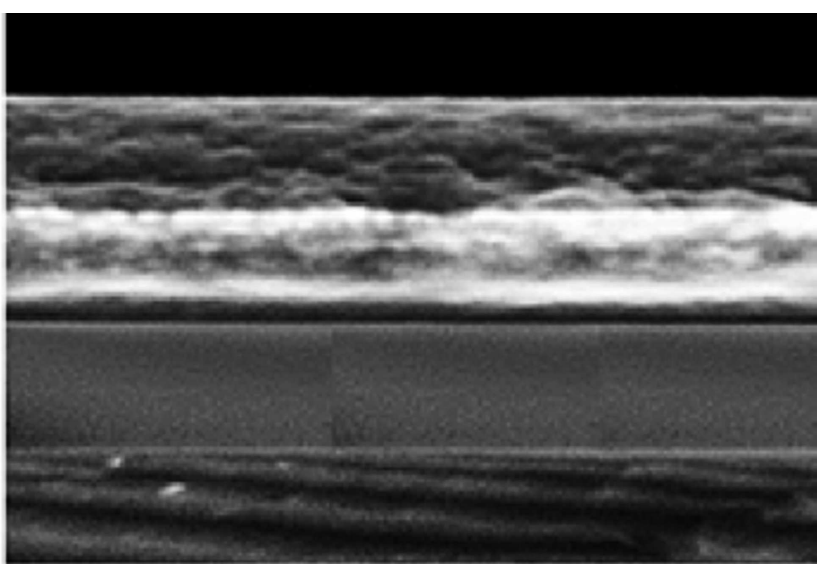

$v=27 \mathrm{~nm} / \mathrm{min}$

$d=405 \mathrm{~nm}$

Рис. 3. Поперечные сечения пленок „закритической“ $(a)$ и ,докритической“ $(b)$ толщины $d$, выращенных при напряжениях смещения $U_{b}=0(a)$ и $-100 \mathrm{~V}(b)$ и различных скоростях осаждения $v$.

зывают с вызванной магнитострикцией деформацией и столбчатой микроструктурой пленок. Дальнейшее увеличение скорости напыления до $27 \mathrm{~nm} / \mathrm{min}$ не приводит к заметному изменению величины „критической“ толщины пленок. Подача отрицательного напряжения смещения $U_{b}=-100 \mathrm{~V}$ на подложку во время осаждения приводит к исчезновению „критической“ толщины в пленках, выращенных при $v=7$ и $14 \mathrm{~nm} / \mathrm{min}$ с толщинами до $980 \mathrm{~nm}$. При этом величина $H_{c}$ изменяется в диапазоне $0.55-0.80$ Ое для $v=7 \mathrm{~nm} / \mathrm{min}$ и $0.15-1.4 \mathrm{Oe}$ для $v=14 \mathrm{~nm} / \mathrm{min}$. Дальнейшее увеличение скорости напыления до $21 \mathrm{~nm} / \mathrm{min}$ приводит к появлению „критической“ ${ }^{\circ}$ толщины $d_{\text {cr }} \approx 520 \mathrm{~nm}$, которая возрастает до $\sim 540$ Ое при увеличении $v$ до $27 \mathrm{~nm} / \mathrm{min}$. При 

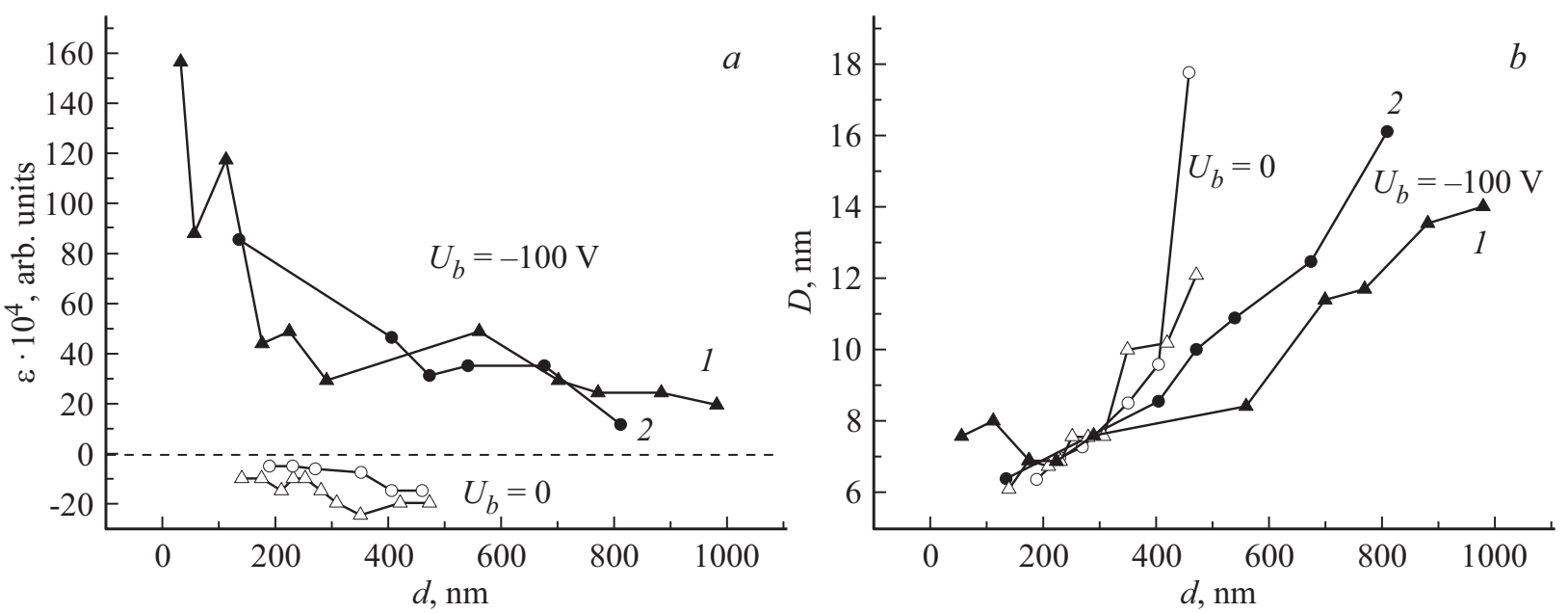

Рис. 4. Зависимости деформации $\varepsilon(a)$ и размера зерна $D(b)$ от толщины пленок $d$, выращенных при $U_{b}=0$ и $-100 \mathrm{~V}$ и скоростях: $1-v=14,2-v=27 \mathrm{~nm} / \mathrm{min}$.

$v=21 \mathrm{~nm} / \mathrm{min}$ максимальное значение $H_{c}=10.2$ Ое и уменьшается до $0.35 \mathrm{Oe}$. Для $v=27 \mathrm{~nm} / \mathrm{min} H_{c}$ изменяется от 9.3 до $1.3 \mathrm{Oe.}$

Прежде, чем переходить к обсуждению результатов, необходимо отметить, что пленки $\mathrm{NiFe}$, осажденные при $U_{b}=0$, имеют поликристаллическую структуру со слабо выраженной текстурой $\mathrm{NiFe}(111)$. Чтобы охарактеризовать зависимость текстуры пленок от параметров осаждения обратимся к рисунку 2, где приведены зависимости коэффициента текстуры $T_{h k l}$ от параметров $v$ и $U$, определяемого по формуле [18]:

$$
T_{h k l}=\frac{I_{h k l} / I_{h k l}^{0}}{1 / h n \sum I_{h k l} / I_{h k l}^{0}},
$$

где $I_{h k l}$ - измеренная интенсивность дифракционной линии $h k l, I_{h k l}^{0}$ - интенсивность линии для порошкового $\mathrm{NiFe}$ из картотеки JCPDS, и $n-$ число использованных рефлексов. При этом рост значений $T_{h k l}$ отражает усиление текстуры $(h k l)$.

Из рис. 2 можно видеть, что при напряжении смещения $U_{b}=-100 \mathrm{~V}$ наблюдается усиление текстуры $\mathrm{NiFe}(111)$ по сравнению со случаем пленок, выращенных на „заземленной“ подложке $\left(U_{b}=0\right)$. Увеличение скорости осаждения ведет к росту текстуры пленок, выращенных при $U=-100 \mathrm{~V}$, и немонотонному уменьшению в случае $U_{b}=0[19,20]$.

Выбор $U_{b}=-100 \mathrm{~V}$ в проведенных исследованиях объясняется тем, что дальнейшее увеличение $U_{b}$ при незначительном улучшении текстуры пленок приводит к заметному снижению скорости роста пленки за счет ее распыления положительными ионами аргона. Наблюдаемое при этом повышение температуры подложки не приводит к заметному изменению структуры пленок [20].

На рис. 3. показаны изображения поперечного сечения пленок, осажденных при различных $v$ и $U_{b}$.

Увеличение скорости осаждения приводит к увеличению количества атомов распыляемой мишени и их энергии. При используемом давлении рабочем газа $\sim 0.2 \mathrm{~Pa}$ длина свободного пробега распыляемых частиц мишени превышала расстояние между мишенью и подложкой и, следовательно, энергия частиц, попадающих на подложку, не изменялась при прохождении от мишени до подложки. Таким образом,увеличение скорости осаждения сопровождалось увеличением миграционной способности адатомов и формированию более однородной микроструктуры пленок. В то же время, бомбардировка растущей пленки положительными ионами $\mathrm{Ar}$ препятствовала формированию столбчатой микроструктуры (рис. $3, b$ ).

Результаты рентгеноструктурного анализа пленок, полученных при $v=14$ и $27 \mathrm{~nm} / \mathrm{min}$, приведены на рис. 4 . Величина межплоскостного расстояния $a_{[h k l]}$ вдоль кристаллографической оси $[h k l]$ определялась по формуле Брэгга-Вульфа $2 a_{[h k l]} \sin \theta=n \lambda$, где $\theta-$ дифракционный угол, $\lambda=0.15418 \mathrm{~nm}$ и $n=1$. Размер зерна определялся по формуле Шеррера $L=\lambda / \beta \cos \theta$, где $\beta$ - уширение дифракционной линии. Зависимость внутренних деформаций $\varepsilon=\Delta a / a$ исследуемых образцов от толщины показана на рис. $4, a$.

Прежде всего, необходимо отметить различие в деформациях пленок, выращенных при $U_{b}=0$ и $-100 \mathrm{~V}$. Видно, что для пленок, выращенных при $U_{b}=0$, характерна деформация сжатия $(\varepsilon<0)$, в то время, как пленки, выращенные при $U_{b}=-100 \mathrm{~V}$ испытывают деформацию растяжения $(\varepsilon>0)$. Магнитомягкие пленки, выращенные при $U_{b}=0$ и $v=14 \mathrm{~nm} / \mathrm{min}$, в ,докритическом“ состоянии $\left(d_{\mathrm{cr}} \leq 220 \mathrm{~nm}\right)$ имеют $\varepsilon \approx-5 \cdot 10^{-4}$, величина которой при переходе в „закритическое“ состояние возрастает до $\varepsilon \approx-10 \cdot 10^{-4}$. Для магнитомягких пленок, выращенных при $U_{b}=-100 \mathrm{~V}$ и $v=27 \mathrm{~nm} / \mathrm{min}$, наблюдается уменьшение $\varepsilon$ от $86 \cdot 10^{-4}$ до $35 \cdot 10^{-4}$ ед. при увеличении толщины пленки до „критической“ $d_{\mathrm{cr}} \approx 520 \mathrm{~nm}$. Дальнейшее увеличение толщины пленки до $810 \mathrm{~nm}$ ведет к уменьшению $\varepsilon$ до $12 \cdot 10^{-4}$ ед. Для пленок, выращенных при $v=14 \mathrm{~nm} / \mathrm{min}$ и $U_{b}=-100 \mathrm{~V}$, величина $\varepsilon$ уменьшается от $156 \cdot 10^{-4}$ до $20 \cdot 10^{-4} \mathrm{c}$ ростом толщины пленки от 30 до $980 \mathrm{~nm}$. При этом переход в „закритическое“ состояние не наблюдается. 

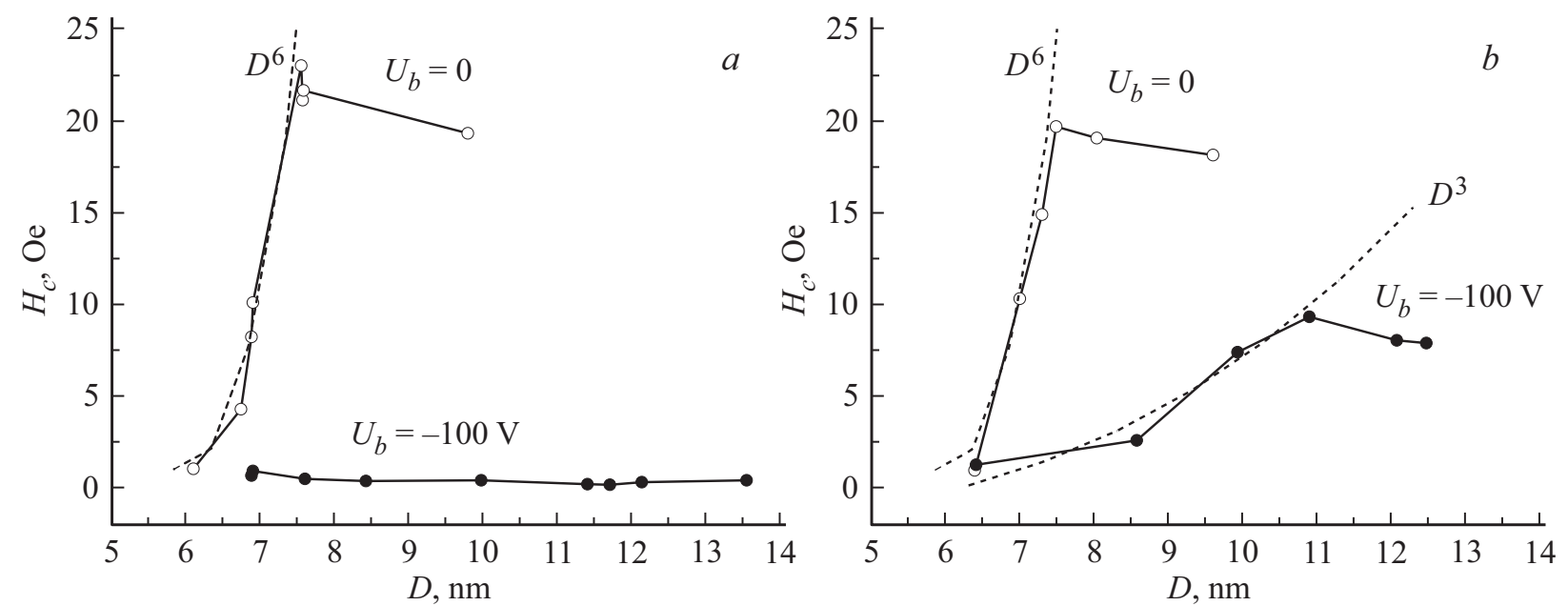

Рис. 5. Зависимости коэрцитивности $H_{c}$ от размера зерна $D$ для пленок, полученных при $U_{b}=0$ и $-100 \mathrm{~V}$ и скоростях $v=14(a)$ и (b) $27 \mathrm{~nm} / \mathrm{min}$.

Таким образом, можно утверждать, что для пленок выращенных при $U_{b}=-100 \mathrm{~V}$ и $v$ от 7 до $27 \mathrm{~nm} / \mathrm{min}$, внутренние деформации не оказывают заметного влияния на переход пленки в „закритическое“ состояние. Полученные результаты согласуются с данными работы [14], в которой для пленок толщиной $1 \mu \mathrm{m}$, осажденных при $U_{b}=-100 \mathrm{~V}$, исчезновение „закритического“ состояния связывается с отсутствием деформаций и переходом от столбчатой микроструктуры к однородной.

Поскольку размер зерна оказывает существенное влияние на величину коэрцитивности [6], рассмотрим, как изменяется размер зерна с ростом толщины пленок (рис. $4, b)$. Независимо от $U_{b}$ и $v$, с ростом толщины пленки размер зерна увеличивается, однако размер зерна пленок, выращенных при $U_{b}=-100 \mathrm{~V}$, растет медленнее и, в соответствии с моделью хаотической анизотропии [7], ведет к смещению $d_{\mathrm{cr}}$ в область больших толщин. Видно, что пленки, выращенные при $U_{b}=0$, переходят в „закритическое“ состояние при толщине пленок $220-270 \mathrm{~nm}$ и размере зерна $D_{\mathrm{cr}} \approx 7 \mathrm{~nm}$. Для пленок, осажденных при $U_{b}=-100 \mathrm{~V}$ и $v=21$ и $27 \mathrm{~nm} / \mathrm{min}$, „критическая““ толщина $\sim 520 \mathrm{~nm}$ и $D_{\text {cr }} \approx 11 \mathrm{~nm}$.

На рис. 5 представлены зависимости коэрцитивности $H_{c}$ от размера зерна $D$ для пленок, полученных при скоростях напыления 14 и $27 \mathrm{~nm} / \mathrm{min}$ при $U_{b}=0$ и $-100 \mathrm{~V}$. Там же приведены рассчитанные зависимости $H_{c} \propto D^{6}$ и $H_{c} \propto D^{3}$ (пунктир).

Видно, что при $v=14 \mathrm{~nm} / \mathrm{min}$ и $U_{b}=0$ (рис. $6, a$ ), зависимость коэрцитивности от размера зерна $H_{c} \propto D^{6}$ при $D \leq 7.5 \mathrm{~nm}$, и $H_{c} \propto 1 / D$ при $D \geq 7.5 \mathrm{~nm}$, что соответствует нанокристаллическим материалам [8]. Подача отрицательного напряжения смещения $U_{b}=-100 \mathrm{~V}$ приводит к усилению текстуры пленки (рис. 2) и изменению зависимости $H_{c}$ от $D$. При $U_{b}=-100 \mathrm{~V}$ $H_{c}$ изменяется от 0.15 до $1.4 \mathrm{Oе}$ во всем диапазоне размера зерна.

Увеличение скорости роста пленок до $27 \mathrm{~nm} / \mathrm{min}$ при $U_{b}=0$ не изменяет нанокристаллическую структуры пленки и зависимость $H_{c} \propto D^{6}$ сохраняется (рис. $5, b$ ). При $U_{b}=-100 \mathrm{~V}$ степенная зависимость $H_{c}(D)$ изменяется с $H_{c} \propto D^{6}$ на $H_{c} \propto D^{3}$, что не противоречит известным данным $[16,17]$ и связано с незначительным улучшением текстуры нанокристаллической пленки, приводящим к появлению однородной магнитной анизотропии.

\section{4. Заключение}

Экспериментально показана возможность получения магнитомягких пленок $\mathrm{NiFe}$ толщиной до $980 \mathrm{~nm}$ подачей отрицательного напряжения смещения на подложку и подбором скорости осаждения. При отсутствии напряжения смещения коэрцитивность $H_{c}$ изменяется $\propto D^{6}$, „критическая“ толщина $d_{\mathrm{cr}} \approx 230 \mathrm{~nm}$ и максимальное значение $H_{c}$ изменяется от 17 до $25 \mathrm{Oе}$ в зависимости от скорости осаждения. Подача отрицательного напряжения смещения приводит к бомбардировке растущей пленки ионами аргона, что улучшает текстуру пленок, уменьшает размер зерна, затрудняет формирование столбчатой микроструктуры и приводит изменению зависимости $H_{c}$ от $D$. При $U_{b}=-100 \mathrm{~V}$ и $v=21$ и $27 \mathrm{~nm} / \min H_{c}$ изменяется $\propto D^{3}$, максимальное значение $H_{c}$ уменьшается до $\sim 8$ Ое и $d_{\text {cr }}$ увеличивается до $\sim 520 \mathrm{~nm}$. Снижение $v$ до 7 и $14 \mathrm{~nm} / \mathrm{min}$ приводит к дальнейшему снижению зависимости $H_{c}$ от $D . C$ ростом толщины пленки до $980 \mathrm{~nm}$ размер зерна увеличивается от 7 до $14 \mathrm{~nm}, H_{c}$ изменяется от 0.15 до $1.4 \mathrm{Oe}$, „критическая“ толщина отсутствует. Следует отметить, что зависимость $H_{c} \propto D^{3}$ в пленках $\mathrm{NiFe}$ наблюдается впервые.

\section{Финансирование работы}

Работа выполнена в рамках государственного задания № 0030-2019-0013 „Спинтроника“. 


\section{Конфликт интересов}

Авторы заявляют, что у них нет конфликта интересов

\section{Список литературы}

[1] Electrochemical nanotechnologies / Eds T. Osaka, M. Datta, Y. Shacham-Diamand. Springer (2009). 279 p.

[2] Б.Г. Лившиц, В.С. Крапошин, Я.Л. Линецкий. Физические свойства металлов и сплавов. Металлургия, М. (1980). $318 \mathrm{c}$.

[3] E. Klokholm, J.A. Aboaf. J. Appl. Phys. 52, 2474 (1981).

[4] N. Amos, R. Fernandez, R. Ikkawi, B. Lee, A. Lavrenov, A. Krichevsky, D. Litvinov, S. Khizroev. J. Appl. Phys. 103, 07E732 (2008).

[5] W.T. Soh, N.N. Phuoc, C.Y. Tan, C.K. Ong. J. Appl. Phys. 114, 053908 (2013).

[6] G. Herzer. IEEE Trans. Magn. 26, 1397 (1990).

[7] G. Wang, C. Dong, W. Wang, Z. Wang, G. Chai, C. Jiang, D. Xue. J. Appl. Phys. 112, 093907 (2012).

[8] M.A. Akhter, D.J. Mapps, Y.Q. Ma Tan, Amanda PetfordLong, R. Doole. J. Appl. Phys. 81, 4122 (1997).

[9] Y. Sugita, H. Fujiwara, T. Sato. Appl. Phys. Lett. 10, 229 (1967).

[10] G. Herzer. Acta Mater. 61, 718 (2013).

[11] V. Svalov, G.V. Kurlyandskaya, B. González Asensio, J.M. Collantes, A. Larrañaga. Mater. Lett. 52, 159 (2015).

[12] X. Li, X. Sun, J. Wang, Q. Liu. JMMM, 377, 142 (2015).

[13] A.V. Svalov, I.R. Aseguinolaza, A. Garcia-Arribas, I. Orue, J.M. Barandiaran, J. Alonso, M.L. Fernández-Gubieda, G.V. Kurlyandskaya. IEEE Trans. Magn. 46, 333 (2010).

[14] Y. Hoshi, M. Kojima, M. Naoe, S. Yamanaka. IEEE Trans. Magn. 18, 1433 (1982).

[15] A.V. Svalov, B. Gonzalez Asensio, A.A. Chlenova, P.A. Savin, A. Larranaga, J.M. Gonzalez, G.V. Kurlyandskaya. Vacuum 119, 245 (2015).

[16] K. Suzuki, G. Herzer, J.M. Cadogan. JMMM 177-181, 949 (1998).

[17] K. Suzuki, R. Parsons, B. Zang, K. Onodera, H. Kishimoto, T. Shoji, A. Kato. AIP Adv. 9, 035311 (2019).

[18] H. Cheng, M. Hon. J. Appl. Phys. 79, 8047 (1996).

[19] A.S. Dzhumaliev, Yu. Nikulin, Yu. Filimonov. MISM 778 (2017).

[20] А.С. Джумалиев, Ю.В. Никулин, Ю.А. Филимонов. ФТТ 58, 1019 (2016).

Редактор К.В. Емиев 